\title{
Reliability of PCR Decontamination Systems
}

\author{
C. Niederhauser, C. Höfelein, B. Wegmüller, J. Lüthy, and U. Candrian
}

Laboratory of Food Chemistry, Institute of Biochemistry, University of Bern, Bern, Switzerland

A major problem in the application of PCR is contamination with material amplified previously. Repeated PCRs result in the accumulation of intact and degraded amplicons and primer artifacts that can contaminate following amplification reactions. Post-PCR UV treatment and pre-PCR uracil DNA glycosylase (UDG) digestion have been recognized to efficiently inactivate or decompose intact amplification fragments. We show here that degraded amplification products and primer artifacts account for decreased sensitivity and may cause false-negative results. Our experiments indicate that partly degraded PCR products and primer artifacts containing sequences homologous to the primer oligonucleotides in the succeeding PCR reaction compete efficiently with sample DNA for the primers. The experiments done in this study may explain unexpectedly low PCR sensitivities reported in an increasing number of publications. In an attempt to solve this problem, we evaluated three post-PCR treatment methods to completely eliminate sequences competing for the amplification primers, namely, 8-methoxypsoralen (MOPS) or hydroxylamine treatment of amplified DNA and use of oligonucleotides containing 5'ChemiClamps. However, all three methods did not sufficiently inhibit artificially produced carryover contaminations. In conclusion, falsepositive results can be eliminated with UDG or UV treatment, but physical barriers are indispensable to avoid the occurrence of false-negative results. he PCR technique has become a powerful and very sensitive tool in a broad field of research, that is, molecular biology, medical and food diagnostics, population genetics, and forensic analysis. A major problem concerning the use of PCR, especially in diagnostic applications, is contamination with amplification products of previous reactions that cause false-positive results. A typical PCR reaction may contain up to $10^{13}$ copies of amplicons. Therefore, the fewer template molecules one is trying to detect, the more one should guard against carryover contaminations. In addition to the use of physical barriers ${ }^{(1)}$ to avoid product carryover, a number of chemical procedures have been designed to eliminate false-positive $\mathrm{PCR}$ results. At present, uracil DNA glycosylase (UDG) digestion $^{(2,3)}$ and UV irradiation ${ }^{(4-6)}$ are used routinely in some laboratories. In addition, other approaches have been described to solve this problem, such as the use of isopsoralen, ${ }^{(7)}$ exonuclease III, ${ }^{(8)} \gamma$ irradiation, ${ }^{(9)}$ restriction enzymes, ${ }^{(10,11)}$ DNase I, ${ }^{(12)}$ hydroxylamine hydrochloride, ${ }^{(13)}$ and 8-methoxypsoralen (Mops). ${ }^{(14)}$

Longo et al. ${ }^{(2)}$ first described the UDG method in which dUTP substitutes for dTTP in the amplification reaction. The incorporation of dUTP allows DNA amplification products of previous PCR reactions to be distinguished from sample DNA. Treatment of reaction mixtures with UDG prior to amplification selectively destroys contaminating amplification products from previous dUTP-PCR reactions. Although the technique has been shown to be effective in controlling carryover contamination, potential problems include (1) incomplete inactivation of UDG activity ${ }^{(15)}$ and thus degradation of dUMP containing strands immediately after synthesis, (2) unspecific UDG activity for nucleotides other than dUMP, ${ }^{(3)}$ (3) inefficient incorporation of dUTP by thermostable DNA polymerases other than Thermus aquaticus DNA polymerase, ${ }^{(16)}$ and (4) lower amplification efficiency with the use of dUTP in some protocols. ${ }^{(13)}$

UV irradiation of DNA results in the formation of pyrimidine dimers and strand breaks and thus hinders amplification products from acting as templates in subsequent PCR reactions. If UV sterilization precedes PCR, it must inactivate all carryover amplicons that are present. $^{(4,6)}$ With the pre-PCR method, reagents susceptible to UV-induced modification must be left out and added after the UV irradiation process. Prolonged irradiation will inactivate the PCR reaction mixture, if all components including Taq DNA polymerase are initially added. ${ }^{(17)}$ Alternatively, we chose postPCR UV irradiation in this study. This leads to cross-linking of amplicons but still allows agarose gel electrophoresis (see below) and, in some cases, restriction enzyme digestion (data not shown).

\section{MATERIALS AND METHODS}

\section{Bacterial Strains}

Escherichia coli JM101 and Listeria monocytogenes $4 \mathrm{~b}$ were grown on tryptic soy agar (Oxoid, Basingstoke, UK) at $37^{\circ} \mathrm{C}$. Bacteria were lysed with lysozyme (Sigma, St. Louis, MO) and proteinase K (Merck, Darmstadt, Germany) as described by Furrer et al. ${ }^{(18)}$

\section{Production of Amplicons for Artificial Contamination}

Oligonucleotides were purchased from Anawa Trading SA (Wangen, Switzer- 
land). The following pair of oligonucleotides were used to amplify a 595-bp DNA fragment of the malB region of $E$. coli: ECO3, 5'-TCGCCACACGCTGACGCTGACCA-3'; and ECO4, 5'-TTACATGACCTCGGTTTAGTTCACAGA-3'. Twentyfive microliters of lysed bacterial suspension was added to $75 \mu \mathrm{l}$ of reaction buffer containing $0.5 \mu \mathrm{M}$ each oligonucleotides, $3.0 \mathrm{mM} \mathrm{MgCl}_{2}, 10 \mathrm{~mm}$ Tris- $\mathrm{HCl}$ (pH 9.0), $50 \mathrm{~mm} \mathrm{KCL}, 0.1 \%$ Triton $\mathrm{X}-100$, $0.01 \%$ gelatin, $200 \mu \mathrm{M}$ each dNTPs, 0.2 $\mu \mathrm{g}$ of BSA, and 2 units of Taq DNA polymerase (Anawa). Forty reaction cycles were performed on a PHC-1 thermal cycler (Techne, Princeton, NJ) with the following temperature program: $30 \mathrm{sec}$ at $95^{\circ} \mathrm{C}, 1 \mathrm{~min}$ at $65^{\circ} \mathrm{C}$, and $1 \mathrm{~min}$ at $72^{\circ} \mathrm{C}$.

\section{Decontamination Treatments}

\section{UV Treatment}

Polypropylene tubes containing amplification products (Sarstedt, no. 72.699) were exposed to UV irradiation for 15 min by placing them directly under the bulbs of a UV Stratalinker 1800 (Stratagene, $254 \mathrm{~nm}$ ).

\section{UDG Treatment}

Reaction mixtures containing 1 unit of UDG (Life Technologies, Basel, Switzerland) were incubated for $10 \mathrm{~min}$ at $37^{\circ} \mathrm{C}$. To stop the reaction, samples were heated to $94^{\circ} \mathrm{C}$ for $7 \mathrm{~min}$ before being subjected to a second round of PCR.

\section{Analysis of Contamination by PCR}

Amplicons from the first round of PCR (Fig. 1) were either UV treated prior to preparing 10 -fold serial dilutions or 10 fold serially diluted before UDG incubation. Treated samples were then used as target DNA in a second round of PCR. malB PCR was performed as described above. The following pair of oligonucleotides was used to amplify a 234-bp DNA fragment of the $h l y A$ region of $L$. monocytogenes: LO1, 5'-CGGAGGTTCCGCAAAAGATG-3'; and LO4, 5'-CCTCCAGAGTGATCGATGTT-3'. Twenty-five microliters of lysed bacterial suspension was added to $75 \mu$ l of reaction buffer containing $0.5 \mu \mathrm{M}$ oligonucleotides, 2.0 $\mathrm{mM} \mathrm{MgCl}_{2}, 10 \mathrm{~mm}$ Tris-HCl (pH 9.0), 50 $\mathrm{mm} \mathrm{KCl}, 0.1 \%$ Triton $\mathrm{X}-100,0.01 \%$ gelatin, 200 each $\mu \mathrm{m}$ dNTPs, $0.2 \mu \mathrm{g}$ of BSA,

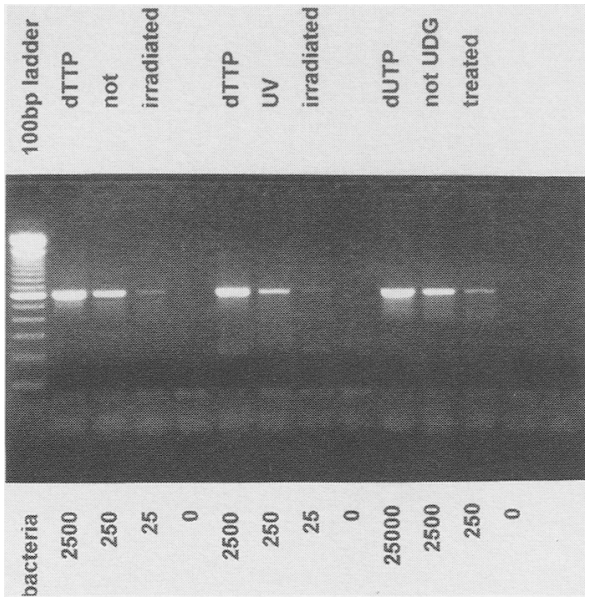

FIGURE 1 Production of amplicons. malB PCR from $E$. coli. Amplification products shown in lanes 2-9 were produced with dTTP; amplicons in lanes 10-13 with dUTP. Because the dUTP reaction is less sensitive, initial target DNA concentration was chosen 10 times higher than in the dTTP reaction.

and 2 units of Taq DNA polymerase. Forty cycles were performed on a PHC-1 thermal cycler (Techne) with segment times of $30 \mathrm{sec}$ at $95^{\circ} \mathrm{C}, 1 \mathrm{~min}$ at $55^{\circ} \mathrm{C}$, and $1 \mathrm{~min}$ at $72^{\circ} \mathrm{C}$.

\section{RESULTS AND DISCUSSION}

\section{Objective of the Study}

We show here that procedures designed to eliminate false-positive results in PCR may lead to reduced sensitivity and falsenegative results. The generation of small degradation products containing sequences complementary to primer oligonucleotides may significantly reduce the free primer concentration in a subsequent PCR. To test this hypothesis, we chose the following stepwise strategy: (1) We produced a range of contamination levels by serial dilution of intact amplicons; (2) the effectiveness of UDG and UV treatments was determined; (3) the effect of degradation products obtained with these treatments on subsequent amplification reactions was measured. These assays were extended to the influence of decomposed primer artifacts as well. (4) Experiments to elucidate the mechanisms of inhibition were performed; and (5) on the basis of these observations and conclusions, procedures to solve the problem were evaluated.
We chose the malB operon from $E$. coli as target sequence. ${ }^{(19)}$ The two oligonucleotides ECO3 and ECO4 yield a 595-bp fragment. For contamination and inactivation experiments, the following templates were used: dTTP amplicon, untreated; dTTP amplicon, UV irradiated; dUTP amplicon, untreated; dUTP amplicon, UDG treated (treatment of reaction mix just prior to PCR); dTTP negative control sample (no template DNA), untreated; dTTP negative control, UV irradiated; dUTP negative control, untreated; dUTP negative control, UDG treated (treatment of reaction mix just prior to PCR). An ethidium bromidestained agarose gel of amplicons prepared for these eight solutions is shown in Figure 1. If dUTP was used instead of dTTP, the sensitivity of the amplification reaction was $\sim 10$ times lower. Therefore, $250 \mathrm{E}$. coli genome copies were used in the case of dTTP and 2500 with dUTP for further experiments.

\section{Artificial Contaminations}

In a first experiment, the artificial introduction of contaminations with dTTP and dUTP malB amplicons was evaluated (Fig. 2, I, A, and B, respectively). The malB PCR fragment, reamplified without prior UV irradiation or UDG incubation, yielded reaction products down to a dilution of $10^{-9}$ and $10^{-7}$, respectively. The difference in detection limits between the two carryover contamination systems could be the result of several factors. First, the described malB PCR system has not been optimized for dUTP incorporation; second dUTP is a somewhat less efficient substrate for Taq DNA polymerase; ${ }^{(3)}$ finally, dUTP amplicons are relatively unstable. The detection limits per se are another point of interest. If it is assumed that a typical PCR reaction produces up to $10^{13}$ amplicons, the sensitivities determined in our experiments were extremely low. A factor yet unidentified in PCR seems to inhibit a sensitive reamplification. There is an additional striking point; The primer artifact bands in reamplification experiments, for both dTTP and dUTP reactions, were very strong. It appears that these primer artifacts were accumulating during the second round of PCR. Primer artifacts were also transferred to the reamplification reaction, together with correct amplicons, and can compete for 


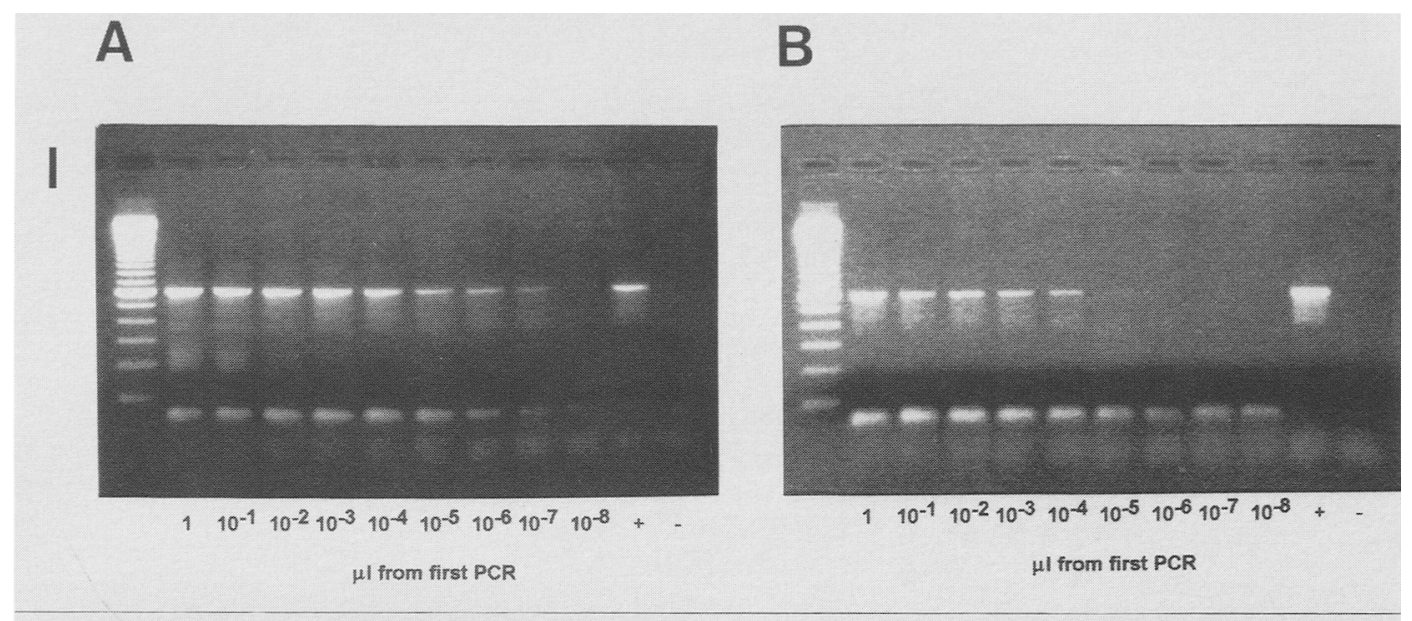

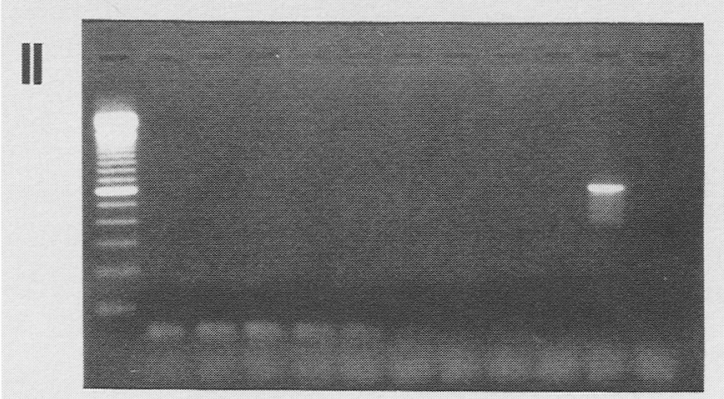

$110^{-1} 10^{-2} 10^{-3} 10^{-4} 10^{-5} 10^{-6} 10^{-7} 10^{-8}+$

$\mu l$ from first PCR

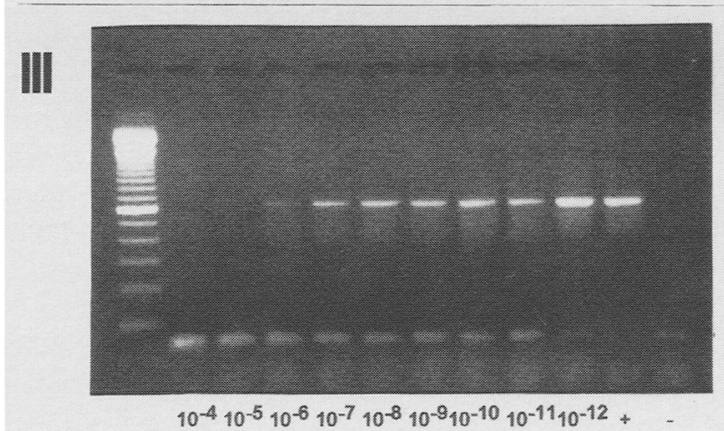

$\mu$ from first $P C R+250$ E.coli

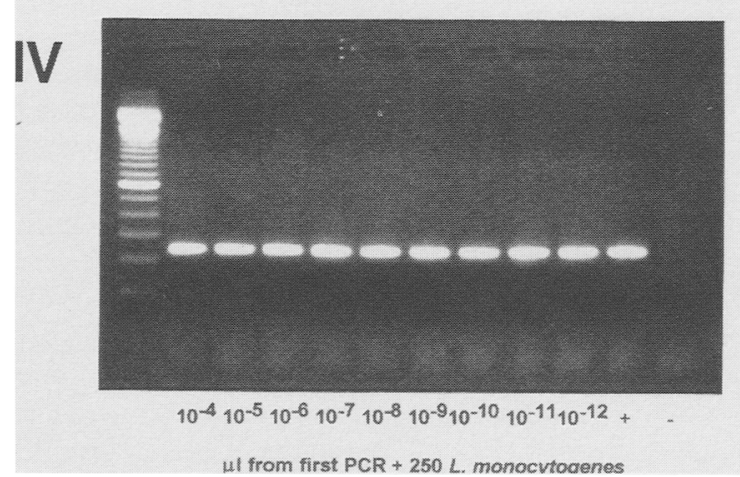

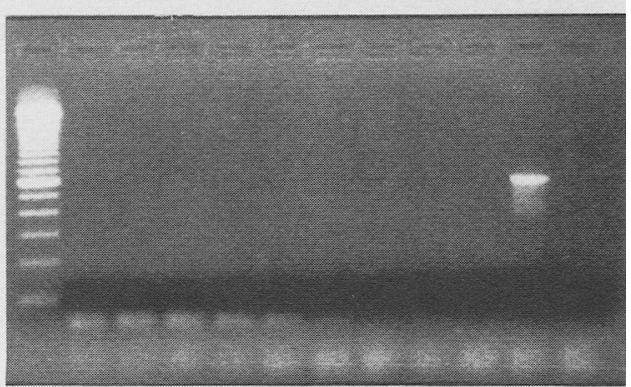

$110^{-1} 10^{-2} 10^{-3} 10^{-4} 10^{-5} 10^{-6} 10^{-7} 10^{-8}+\cdots$

$\mu l$ from first PCR

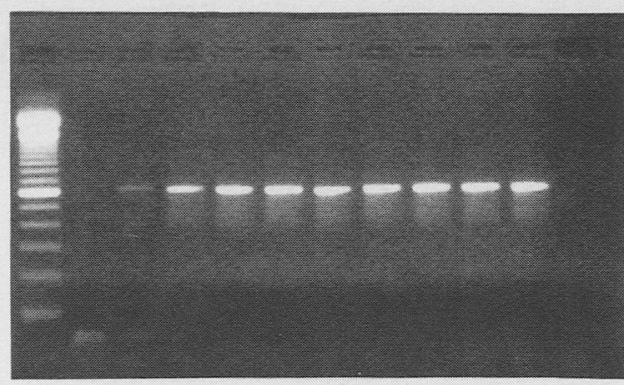

$10^{-4} 10^{-5} 10^{-6} 10^{-7} 10^{-8} 10^{-9} 10^{-10} 10^{-11} 10^{-12}+$

$\mu 1$ from first PCR +2500 E.coli

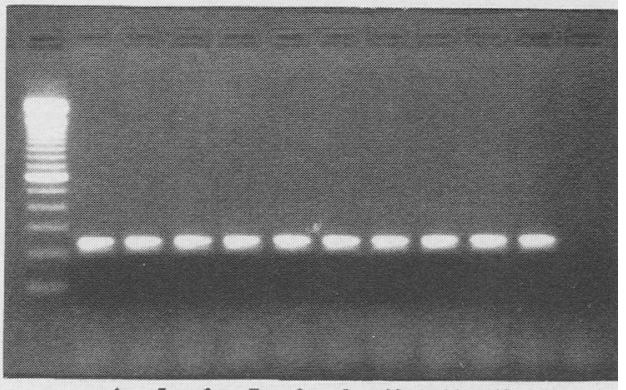

$10^{-4} 10^{-5} 10^{-6} 10^{-7} 10^{-8} 10^{-9} 10^{-10} 10^{-11} 10^{-12}+$

ul from first PCR $+250 L$. monocvtocienes

FIGURE 2 (A) UV treatment experiments. (B) UDG treatment experiments. Reamplification of amplicons with the malB PCR system. Amplicons from the first PCR reaction (Fig. 1) were either UV treated prior to 10-fold serial dilution or 10-fold serially diluted before UDG incubation, and they were used as target DNA for the following experiments: (I) Amplicons not UV or UDG treated; (II) amplicons UV or UDG treated; (III) amplicons UV or UDG treated (addition of $250(A)$ and $2500(B) E$. coli genomes, respectively). (IV) Amplicons UV or UDG treated (addition of 250 L. monocytogenes genomes to both reactions, hlyA-PCR). Numbers at the bottom of the panels indicate microliters of reaction product from first PCR added to the second PCR. Dilution factors of first PCR material thus are 100-fold higher. 
the primer oligonucleotides, thus decreasing the sensitivity of the PCR reaction.

\section{Efficiency of Amplicon Inactivation}

In the second experiment, successful inactivation of carryover contaminations was demonstrated. UDG incubation prior to reamplifying the malB DNA fragment resulted in an elimination of positive results upon reamplification with dilutions up to $10^{-2}$ of the first round of amplification (Fig. 2, II, B). The same result was obtained with UV-treated DNA fragments (Fig. 2, II, A). These findings are in good agreement with observations obtained by other groups. ${ }^{(3,4,20)}$ The use of UDG digestion resulted in an at least $10^{8}$-fold reduction of contaminating amplicons, whereas UV treatment reduced contamination by a factor of $10^{9}$ or more. Because most false-positive results observed in both research and diagnostic testing facilities seem to arise from carryover of as little as $10-10,000$ copies, a procedure that provides complete sterilization of at least $10^{8}-10^{9}$ copies is very effective for decontamination. ${ }^{(20,21)}$

\section{Inhibition of Subsequent Amplifications by UV- or UDG-Treated Amplicons}

In the third experiment, inhibition of PCR amplification of 250 and 2' $500 \mathrm{E}$. coli genome copies by UV- or UDGtreated amplicons was shown (Fig. 2, III, $A$ and $B$, respectively). UV-irradiated amplicons of a first-round amplification, added to PCR reactions containing 250 E. coli templates, inhibited successful amplification in dilutions as high as $10^{-8}$. A dilution of $10^{-7}$ inhibits the succeeding PCR reaction completely (Fig. 2, III, A). Experiments performed after addition of UDG-digestion amplicons showed similar results (Fig. 2, III, B). It is noteworthy that high dilutions of firstround PCR amplification products do not yield visible crossover contamination signals (Fig. 2, I) but are able to inhibit succeeding amplification reactions when degraded (Fig. 2, III). These results show that small amounts of sample DNA, as in most cases of diagnostic applications, can be hindered from successful amplification by minute amounts of degraded amplicons of a previous reaction. The total inhibition of PCR amplification was overcome when high numbers of template copies $\left(10^{6} \mathrm{E}\right.$. coli) were added. Therefore, the use of concentrated positive control samples in diagnostic kits might cover lacking sensitivity caused by cross-contamination with partly decomposed products of an earlier reaction.

\section{Specificity of Inhibition}

In a further experiment we evaluated the sequence specificity of the above-mentioned inhibition. If an $L$. monocytogenes PCR amplification was contaminated with degraded $E$. coli amplicons, no inhibitory effect was seen (Fig. 2, IV). This experiment supports the hypothesis that PCR products and small truncated PCR products might cause the inhibition by competing with the template DNA for the specific primer oligonucleotides. With a PCR system containing two internal oligonucleotides for nested primer PCR, we evaluated the influence of internal sequences on the amplification reaction. Serial dilutions of internal PCR fragments were added to reactions containing the outer primers and 250 copies of template DNA. The efficiency of the subsequent amplification was not reduced even with a high concentration of nested primer PCR product or nested primer artifacts $(1 \mu$ l of previous reaction in $100 \mu \mathrm{l}$ of new reaction). But primer artifacts produced by the outer oligonucleotides strongly inhibited a succeeding PCR with the same primers even at very high dilutions (10 pl of a preceding reaction in $100 \mu$ l of a new reaction). These results show that sequences complementary to the primers caused the inhibition and suggest that primer artifact contamination is a problem as serious as amplicon contamination, by leading to false-negative results.

\section{Amplification Artifacts (e.g., Primer Products) Behave Like Degraded Amplicons}

Experiments with primer artifacts from negative control samples (Fig. 3) were performed as described above for amplicons (Fig. 2). The negative control sample (Fig. 1) containing high levels of primer artifacts was used as starting material. Tenfold serial dilutions of that material were used to examine our hypothesis that primer artifact products added to a new reaction are able to compete for primer oligonucleotides with the template DNA.
As expected, no bands were visible with untreated, UV-irradiated, or UDGdigested primer artifacts added only to a second round of PCR (Fig. 3, I,II).

The inhibition of the amplification of 250 and $2500 \mathrm{E}$. coli genomes by treated (UV and UDG, respectively) primer artifacts was evaluated in a further experiment (Fig. 3, III). UV-irradiated primer artifact diluted down to $10^{-8}$ still inhibited the amplification of $250 \mathrm{E}$. coli genomes completely; with UDG-digested artifacts, an inhibition was seen down to a dilution of $10^{-7}$. This assay shows clearly that UV- and UDG-treated negative control samples may have a very strong inhibitory effect on subsequent amplification reactions.

Finally, the sequene specificity of the inhibition was shown (Fig. 3, IV). No inhibition of the amplification reaction by E. coli PCR primer artifacts occurred in a L. monocytogenes PCR.

\section{Conclusions Drawn From Artifactual Carryover Contamination Experiments}

Our data indicate that partly degraded products and primer artifacts of a previous PCR reaction are able to suppress amplification of template DNA, probably by competing for amplification primers or blocking template DNA. In a carryover contamination, intact or decomposed PCR products, primer artifacts are transferred equally. Primer artifacts, normally ranging from $50-70$ bp in size, are difficult to eliminate once they have contaminated a laboratory.

If not performed at the highest standard possible, PCR probably has greater potential for generating false-positive, or as shown in this study, false-negative, results than most other assays. False-positive results in PCR assays most likely arise from carryover of amplicons of previous reactions or cross-contamination between samples. False-negative results are far more problematic than false-positive ones; they may be the result of the use of primers of insufficient homology to the taret DNA, the presence of inhibitory material in the template DNA preparation, insufficient PCR amplification, or, as shown in this study, carryover contaminations. Routinely used seminested and nested PCR protocols enhance the problem of carryover contamination, as an additional step of amplicon transfer has to be performed. 


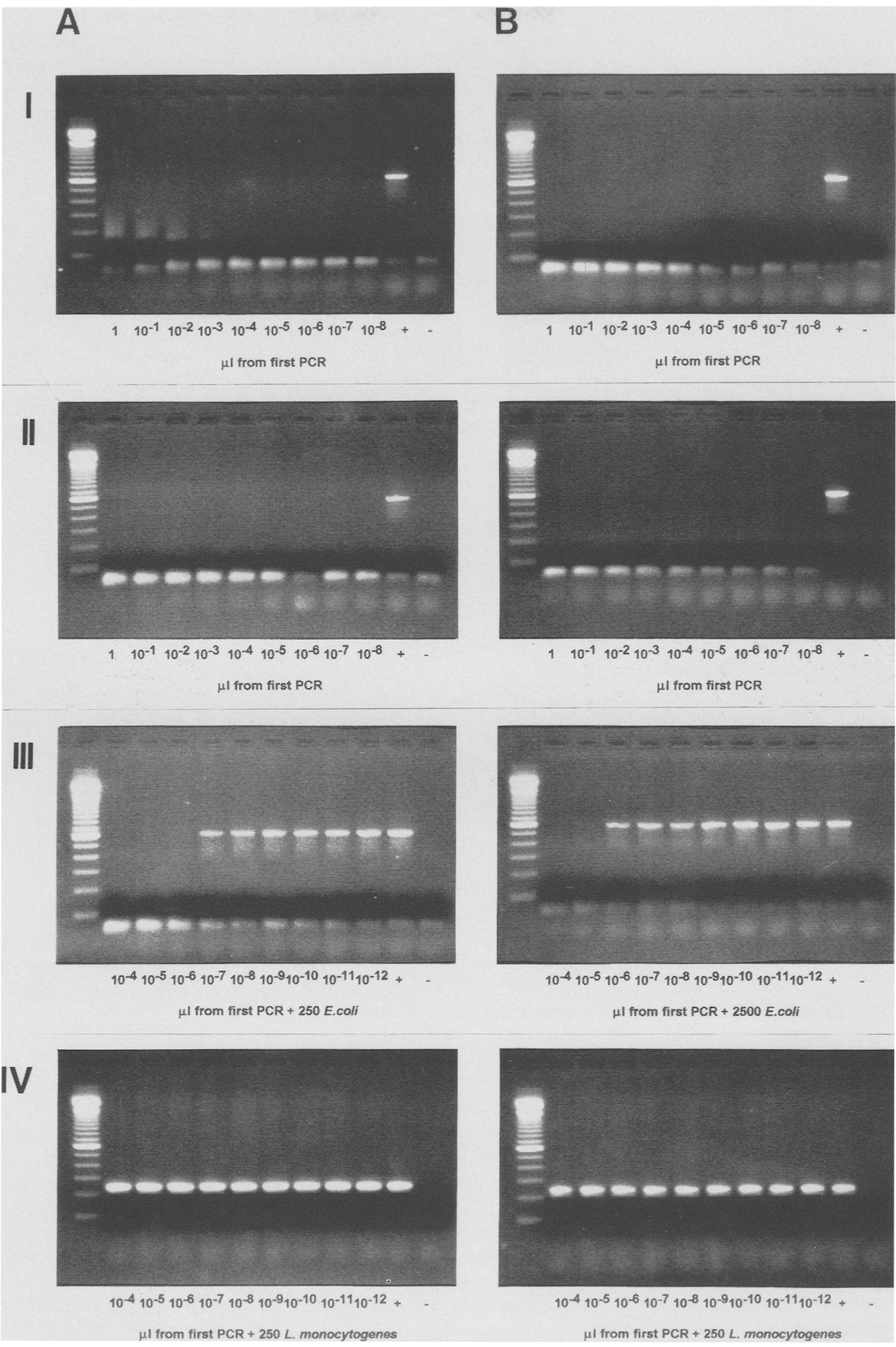

FIGURE $3(A)$ UV treatment experiments. $(B)$ UDG treatment experiments. Reamplification of negative controls of the amplicon production with the malB system. Amplicons from the first PCR reaction (Fig. 1) were either UV treated prior to 10-fold serial dilution or 10-fold serially diluted before UDG digestion, and they were used as target DNA for the following assays: (I) Amplicons not UV or UDG treated; (II) amplicons UV or UDG treated; (III) amplicons UV or UDG treated. Addition of $250(A)$ and $2500(B) E$. coli genomes, respectively. (IV) Amplicons UV or UDG treated (addition of $250 \mathrm{~L}$. monocytogenes genomes to both reactions, hlyA-PCR). Tenfold serial dilutions of amplicons and additional target DNA were as in Fig. 2. 
In an international large-scale PCR quality study, $9.3 \%$ false-positive and $7.4 \%$ false-negative results were observed. ${ }^{(22)}$ Some of the 27 laboratories failed to perform successful amplification with samples containing 10,000 copies of template DNA. In another interlaboratory study, false-negative rates of $10-98 \%$ were obtained. ${ }^{(23)}$ In the last few months, several publications stated increasing numbers of false-negative results or unexpectedly low sensitivities of different PCR amplification reactions. ${ }^{(24,25)}$ It is often argued that inhibitory substances might be the origin of the decreasing sensitivities, but we believe that false-negative results and decreasing sensitivities may be caused by contamination with degraded amplicons and primer artifacts.

\section{Evaluation of Different Approaches in Eliminating False Negatives}

The experiments presented above show that UDG digestion of uridine-containing PCR amplicons and UV irradiation of PCR products are not able to solve the problem of carryover contamination, as false-negative results may appear. A PCR decontamination system must also prevent competition for primers and blocking of template DNA by partly degraded DNA contaminants. To solve this problem, we tested three sterilization systems: Addition of MOPS in combination with long-wave UV irradiation; ${ }^{(14)}$ hydroxylamine hydrochloride treatment; ${ }^{(13)}$ and use of oligonucleotides containing ChemiClamps at their $5^{\prime}$ ends (trademark of Appligene, Illkirch, France). These three modification techniques have the potential to prevent hybridization between primers and treated amplicons or primer artifacts in subsequent reactions.

Psoralens are known to intercalate into double-stranded nucleic acids and to form covalent interstrand cross-links after photoactivation with UV light at $320-400 \mathrm{~nm}$. Thus, PCR products cannot be denatured and may not serve as templates anymore. Meier et al. ${ }^{(14)}$ described investigations on the use of MOPS before PCR to inactivate bacterial DNA contaminating different Taq DNA polymerases. They produced a 920-bp fragment in their study. In our post-PCR experiments, the recommended concentrations of MOPS $(25 \mu \mathrm{g} / \mathrm{ml})$ plus irradiation at $365 \mathrm{~nm}$ for $5 \mathrm{~min}$ did not suffi- ciently block our 595-bp fragment for further amplification reactions. Even the use of higher concentrations of MOPS (up to $250 \mu \mathrm{g} / \mathrm{ml}$ ) inhibited the reamplificiation reaction only slightly, and a strong accumulation of primer artifacts was observed (data not shown). Using a 131-bp fragment from $L$. monocytogenes, treated exactly according to the protocol of Meier et al., ${ }^{(14)}$ absolutely no inhibition was observed. Even MOPS concentrations of up to $800 \mu \mathrm{g} / \mathrm{ml}$ did not yield sufficient sterilization of the 131-bp amplicon. The smaller the amplified PCR fragment is, the less effective is MOPS treatment, which means that the method does not eliminate primer artifacts that may cause false-negative results.

Treatment of PCR products with hydroxylamine modifies DNA chemically and should prevent amplicons from serving as effective target in subsequent PCR reactions. Azlanzadeh ${ }^{(13)}$ used concentrations between 100 and $500 \mathrm{~mm}$ to sterilize a 92- and a 156-bp fragment, respectively. He found that concentrations of hydroxylamine hydrochloride of 250 mM or higher effectively modify amplicons and thus prevent their amplification in subsequent $P C R$ reactions. We thoroughly tested this method with the recommended reaction conditions and some modifications, but we were unable to verify the results reported by Azlanzadeh. However, Azlanzadeh chose assumptions for the preparation of amplicon dilutions that are untenable when considering the amount of primers used for amplification $(\sim 100$ times less than product reported). With our PCR systems we were not able to observe any significant reduction of reamplification of hydroxylamine-treated amplicons (data not shown).

ChemiClamps consist of a photoactivable intercalating agent added to the $5^{\prime}$ end of the primers. After UV irradiation, both strands should be covalently linked together and thus be resistant to denaturation. Our investigations with ChemiClamps suggested that interstrand crosslinking of PCR products occurs at a limited degree only, as we were not able to detect a significant reduction of signal intensities upon reamplification of UV treated amplicons.

\section{CONCLUSIONS}

The use of physical barriers as suggested by Kwok and Higuchi ${ }^{(1)}$ currently seems to be the most efficient method to avoid carryover contaminations. This approach is sufficient to eliminate contamination problems in our laboratory.

In diagnostic kits, PCR-positive controls containing up to $10^{5}$ bacteria per reaction are frequently used. In contrast, naturally contaminated clinical, food, or environmental samples often contain very few bacteria. The accumulation of partially degraded PCR amplicons and primer artifacts may lead to decreased PCR sensitivity and the appearance of false-negative results for test samples that might not be recognized because of the use of concentrated positive controls still producing intense results.

It cannot be stressed enough that multiple negative controls are an essential part of proper PCR protocols. In addition, weak positive controls should be intergrated into the PCR procedures. The occurrence of false-negative results is not always easy to determine and often requires comparison with diagnostic methods other than PCR.

\section{ACKNOWLEDGMENTS}

We thank P. Burkalter for critical discussion of the final manuscript.

\section{REFERENCES}

1. Kwok, S. and R. Higuchi. 1989. Avoiding false positives with PCR. Nature 339: 237-238.

2. Longo, M.C., M.S. Berninger, and J.L. Hartley. 1990. Use of uracil DNA glycosylase to control carry-over contamination in polymerase chain reactions. Gene 93: 125-128.

3. Pang, J., J. Modlin, and R. Yolken. 1992. Use of modified nucleotides and uracilDNA glycosylase (UNG) for the control of contamination in the PCR-based amplification of RNA. Mol. Cell. Probes 6: 251256.

4. Sarkar, G. and S.S. Sommer. 1990. Shedding light on PCR contamination. Nature 343: 27.

5. Ou, C.Y., J.L. Moore, and G. Schochetman. 1991. Use of UV irradiation to reduce false positivity in polymerase chain reaction. BioTechniques 10: 442-445.

6. Pao, C.C., J.J. Hor, P.L. Tsai, and M.Y. Horng. 1993. Inhibition of in vitro enzymatic DNA amplification reaction by ultra-violet light irradiation. Mol. Cell. Probes 7: 217-219.

7. Cimino, G.D., K.C. Metchette, J.W. Tessman, J.E. Hearst, and S.T. Isaacs. 1990. 
Post-PCR sterilization: A method to control carryover contamination for the polymerase chain reaction. Nucleic Acid Res. 19: 99-107.

8. Sheng Zhu, Y., S.T. Isaacs, G.D. Cimino, and J.E. Hearst. 1991. The use of exonuclease III for polymerase chain reaction sterilization. Nucleic Acid Res. 19: 2511.

9. Deragon, J.-M., D. Sinnett, G. Mitchell, M. Potier, and D. Labuda. 1990. Use of $\gamma$ irradiation to eliminate DNA contamination for PCR. Nucleic Acid Res. 18: 6149.

10. DeFilippes, F.M. 1991. Decontaminating the polymerase chain reaction. BioTechniques 10: 26-30.

11. Dougherty, R.M., P.E. Phillips, S. Gibson, and L. Young. 1993. Restriction endonuclease digestion eliminates product contamination in reverse transcribed polymerase chain reaction. J. Virol. Methods 41: 235-238.

12. Furrer, B., U. Candrian, P. Wieland, and J. Lüthy. 1990. Improving PCR efficiency. Nature 346: 324.

13. Azlanzadeh, J. 1993. Application of hydroxylamine hydrochloride for post-PCR sterilization. Mol. Cell. Probes 7: 145-150.

14. Meier, A., D.H. Persing, M. Finken, and E. Böttger. 1993. Elimination of contaminating DNA within polymerase chain reaction reagents: Implications for a general approach to detection of uncultured pathogens. J. Clin. Microbiol. 31: 646-652.

15. Thornton, C.G., J.L. Hartley, and A. Rashtchian. 1992. Utilizing uracil DNA glycosylase to control carryover contamination in PCR: Characterization of residual UDG activity following thermal cycling. BioTechniques 13: 180-183.

16. Slupphaug, G., I. Alseth, I. Eftedal, G. Volden, and H.E. Krokan. 1993. Low incorporation of dUMP by some thermostable DNA polymerases may limit their use in PCR amplifications. Anal. Biochem. 211: 164-169.

17. Frothingham, R., R.B. Blitchington, D.H. Lee, R.C. Greene, and K.H. Wilson. 1992. UV adsorption complicates PCR decontamination. BioTechniques 13: 208-210.

18. Furrer, B., U. Candrian, Ch. Höfelein, and J. Lüthy. 1991. Detection and identification of Listeria monocytogenes in cooked sausage products and in milk by in vitro amplification of haemolysin gene fragments. J. Appl. Bacteriol. 70: 372-379.

19. Candrian, U., B. Furrer, Ch. Höfelein, R. Meyer, M. Jermini, and J. Lüthy. 1991. Detection of Escherichia coli and identification of enterotoxigenic strains by primerdirected enzymatic amplification of specific DNA sequences. Int. J. Food Microbiol. 12: 339-352.

20. Rys, P.N. and D.H. Persing. 1993. Preventing false positives: Quantitative evaluation of three protocols for inactivation of polymerase chain reaction amplification products. J. Clin. Microbiol. 31: 2356-
2360.

21. Isaacs, S.T., J.W. Tessman, K.C. Metchette, J.E. Hearst, and G.D. Cimino. 1991. Post PCR-sterilization: Development and application to an HIV-1 diagnostic assay. Nucleic Acid Res. 19: 109-116.

22. Bootman, J.S. and P.A.J. Kitchin. 1992. An international collaborative study to assess a set of reference reagents for HIV-1 PCR. J. Virol. Methods 37: 23-42.

23. Noordhoek, G.T., A.H. Kolk, G. Bjune, D. Catty, J.W. Dale, P.E.M. Fine, P. GodfreyFaussett, S. Cho, T. Shinnick, S.B. Sevenson, S. Wilson, and J.D.A. Embden. 1994. Sensitivity and specificity of PCR for detection of Mycobacterium tuberculosis: A blind comparison study among seven laboratories. J. Clin. Microbiol. 32: 277-284.

24. Kluytmans, J.A.J.W., W.H.F. Goessens, J.W. Mouton, W.G.V. Quint, L. Habbema, E. Stolz, and J.H.T. Wagenvoort. 1993. Evaluation of clearview and magic lite test, polymerase chain reaction, and cell culture for detection of Chlamydia trachomatis in urogenital specimens. J. Clin. Microbiol. 31: 3204-3210.

25. Palmer, C.J., Y. Tsai, C. Paszko-Kolva, C. Mayer, and L.R. Sangermano. 1993. Detection of Legionella species in sewage and ocean water by polymerase chain reaction, direct fluorescent-antibody, and plate culture methods. Appl. Environ. Microbiol. 59: 3618-3624.

Received May 6, 1994; accepted in revised form July 12, 1994. 


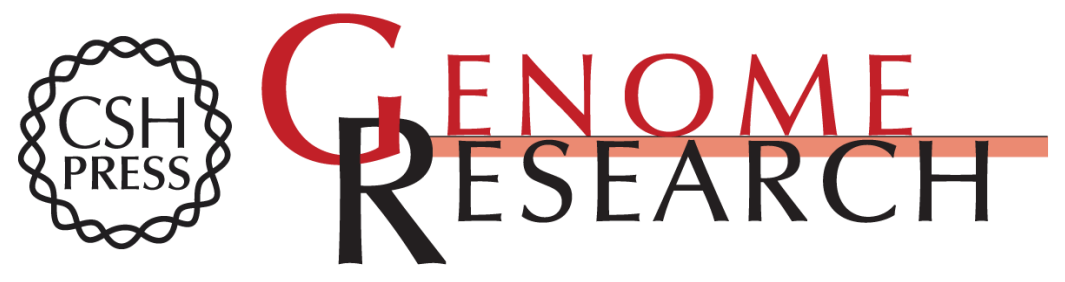

\section{Reliability of PCR decontamination systems.}

C Niederhauser, C Höfelein, B Wegmüller, et al.

Genome Res. 1994 4: 117-123

References This article cites 25 articles, 5 of which can be accessed free at:

http://genome.cshlp.org/content/4/2/117.full.html\#ref-list-1

\section{License}

Email Alerting Receive free email alerts when new articles cite this article - sign up in the box at the Service top right corner of the article or click here.

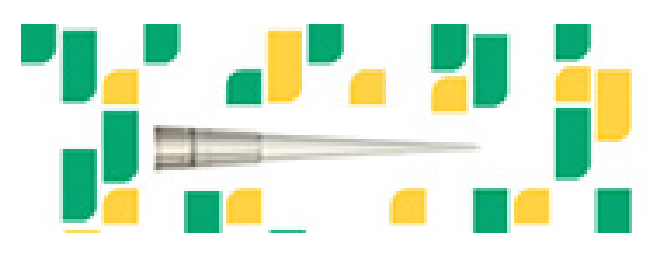

To subscribe to Genome Research go to: https://genome.cshlp.org/subscriptions 